\title{
Evaluation of Pressure Ulcer Among the Critically Ill Patients Admitted in a Tertiary Hospital
}

\author{
B HOSSAIN $^{\mathrm{a}}$, AAMAMUN ${ }^{\mathrm{b}}$, HA RAZI $^{\mathrm{c}}$, NI RAISUL ${ }^{\mathrm{d}}$
}

\begin{abstract}
Background: All over the world pressure ulcer is a significant health care problem due to high morbidity and mortality rates and also high health care cost. This study was carried out with the objectives to identify the characteristics and associated factors of pressure ulcer among the critically ill patients admitted in a tertiary military hospital. Few studies have been conducted on pressure ulcer in Bangladesh and very few in military hospitals.
\end{abstract}

Methodology: This was a cross sectional study conducted among purposively selected 53 critically ill admitted pressure ulcer patients in CMH Dhaka from 01 July 2018 to 31 December 2018 and data were collected by face to face interview and checklist.

Results: Among the study population half (50.9\%) were aged between 61-80 years with the mean age 69.13 years. The most common anatomical site of pressure ulcer were buttock (51.9\%) followed by sacrum (38.5\%) and 30.2\% had multiple pressure ulcer. Among the critically ill patients, $81.1 \%$ had developed pressure ulcer after admission into hospital. The most common place of pressure ulcer was geriatric $\mathrm{HDU}$ (30.2\%) and officers ward (18.9\%). Among the pressure ulcer patients $79.2 \%$ were male. Most common stage of pressure

\section{Introduction}

Pressure ulcer are a very common problem for individuals with restricted mobility. Despite the current treatment and prevention attempts, pressure ulcer remains a serious medical problem commonly found among hospitalized individuals ${ }^{1}$.

Bony prominences are the most common site for developing pressure ulcer ${ }^{2}$. According to National

a. Maj Dr Bulbul Hossain, MPH (DAMS, MS 10, Army Headquarters, Dhaka Cantonment)

b. Lt Col Dr Abdullah Al Mamun, MPH (AMS, MS 10, Army Headquarters, Dhaka Cantonment)

c. Maj Dr Habib Al Razi, MPH (DAMS, MS 10, Army Headquarters, Dhaka Cantonment)

d. Maj Dr Nurul Islam Raisul (Gd spl in Radiology, Adhoc CMH BUSMS)

Address of Correspondence: Maj Bulbul Hossain, MPH, DAMS, MS 10, Army Headquarters, Dhaka Cantonment, Cell No: 01717370904, 01769117128, Email: bulbulniel@gmail.com

Received: 17 August, 2020

Accepted: 23 June, 2021 ulcer were stage II (66.0\%) followed by stage I (18.9\%), stage III (13.2\%) and stage IV (1.9\%). All of them were bedridden and half (50.9\%) were completely immobile. According to Braden Scale, about half (50.9\%) had high risk for development of pressure ulcer followed by moderate risk (26.4\%) and there were none beyond risk. About three fourth (73.6\%) of pressure ulcer patients had hypertension \& cerebrovascular diseases. Age group of 60-90 years, SSC \& above educational group, male sex, immobility, low Braden score group patients are statistically significant $(p<0.05)$, and hypertensive and cerebrovascular diseased patients are not statically significant $(p>0.05)$ but having clear trends to be associate factors of pressure ulcer.

Conclusion: The number of pressure ulcer were increasing with the increase of age. The higher age, male sex, immobilization, low Braden score, hypertension, and cerebrovascular diseased patients were more prone for development of pressure ulcer among the critically ill patients.

Key word: Pressure ulcer, Critically ill patients, Bedridden, Immobilization, Braden Scale

(J Bangladesh Coll Phys Surg 2022; 40: 23-30) DOI: https://doi.org/10.3329/jbcps.v40i1.57054

Pressure Ulcer Advisory Panel, the incidence of pressure ulcer in the USA ranged in acute care settings from $0.4 \%$ to $38 \%$, in long term care $2.2 \%$ to $23.9 \%$, and in home care $0 \%$ to $17 \%{ }^{3}$. Pressure ulcer prevalence in hospital ranging in Europe, USA, Canada and Australia are from $8.3 \%$ to $25.1 \%{ }^{4}$. In the UK, several large multicenter studies showed pressure sore prevalence varies from $6.6 \%$ to $18.6 \% \%^{5}$. The incidence of pressure ulcer in Asian countries was considered high ranging from $2.1 \%$ to $31.3 \%$ in $\mathrm{ICU}^{6}$.

Approximately $70 \%$ of all pressure ulcer occurred in elders. $60 \%$ of pressure ulcer are developed in the acute care setting usually within the first two weeks of hospitalization and $15 \%$ of elderly patients will develop pressure ulcers within the first week of hospitalization ${ }^{7} .1$

Several adverse effects such as increased mortality, increased risk of infection, delayed wound healing, increased use of hospital resources, increased patient 
care costs, increased patients' length of hospital stay, pain and suffering and lowered quality of life are caused by pressure ulcers that has been showed in several previous studies. ${ }^{8}$

In the set-up of Combined Military Hospital, Dhaka, among the critically ill admitted patients, still some associated factors are available that contribute to high occurrence of pressure ulcer.

\section{Methods and Materials}

Cross sectional study was undertaken to assess the characteristics and associated factors of pressure ulcer among the critically ill patients admitted in Combined Military Hospital, Dhaka. The duration of the study was 06 months, commencing from 01 July 2018 to 31 December 2018. All diagnosed pressure ulcer patients admitted in Critical Care Centre, HDU complex, Neurosurgery, Neuromedicine, Burn and plastic, Orthopedic and Officers ward were included as study population. Within the study period, total 53 critically ill diagnosed pressure ulcer patients have been taken as sample. Patients are confined in bed having state of actual or potential risk of life- threatening health problem are considered as critically ill patients. Damage to the skin and/or deeper tissue by pressure effect which can be seen as diagnosed by physician was taken as pressure ulcer. Purposive sampling technique was adopted. Those who gave informed consent, both sex and those who have developed pressure ulcer are included in the study. Unwilling and psychologically abnormal patients are excluded from the study. A semistructured questionnaire was prepared to collect necessary information. A checklist was made to collect information regarding number of pressure ulcer, staging of pressure ulcer, status of dehydration and Braden scale for predicting pressure ulcer risk. The Braden Scale is measured for predicting pressure ulcer risk by using six criteria named sensory perception, moisture, activity, mobility, nutrition and friction $\&$ shear. Score 9 or less indicates severe risk, 10-12 indicates high risk, 13-14 indicates moderate risk, 15-18 indicates mild risk and 19-23 indicates no risk. Informed consent was taken after explaining the purpose of the study to the respondents. As per selection criteria of the study, data collection was carried out by the researcher through face to face interview by asking question in Bangla.

\section{Results:}

Socio-demographic characteristics

Out of 53-study population, majority $27(50.9 \%)$ were in the age group of 61-80 years followed by $12(22.6 \%)$ study population were in 81-100 years of age group. The mean age of the study population were 69.13 years with standard deviation \pm 17.587 years. Among them male were $42(79.2 \%)$ and 11 (20.8\%) were female, all (100\%) were Muslim (Table I).

\section{Table-I}

Socio-demographic characteristics of the study population. $(n=53)$

\begin{tabular}{llcc} 
Characteristics & Categories & Frequency & Percentage \\
\hline \multirow{5}{*}{ Age in years } & $20-40$ & 5 & 9.4 \\
& $41-60$ & 8 & 15.1 \\
Sex & $61-80$ & 27 & 50.9 \\
& $81-100$ & 12 & 22.6 \\
Educational status & e"101 & 1 & 1.9 \\
& Male & 42 & 79.2 \\
& Female & 11 & 20.8 \\
& Illiterate & 2 & 3.8 \\
& Primary & 3 & 7.5 \\
& Secondary & 13 & 24.5 \\
& SSC & 12 & 22.6 \\
& HSC & 6 & 11.3 \\
& Degree or above & 16 & 30.2 \\
Marital status & Married & 45 & 84.9 \\
& Widow & 4 & 7.5 \\
& Widower & 2 & 3.8 \\
& Single & 2 & 3.8 \\
\hline
\end{tabular}

Majority 29 (54.7\%) of study population were retired followed by $11(20.8 \%)$ of study population were housewife. Among them 6 (11.3\%) were serving personnel, $4(7.5 \%)$ were farmer and $3(5.7 \%)$ were businessman (Figure I).

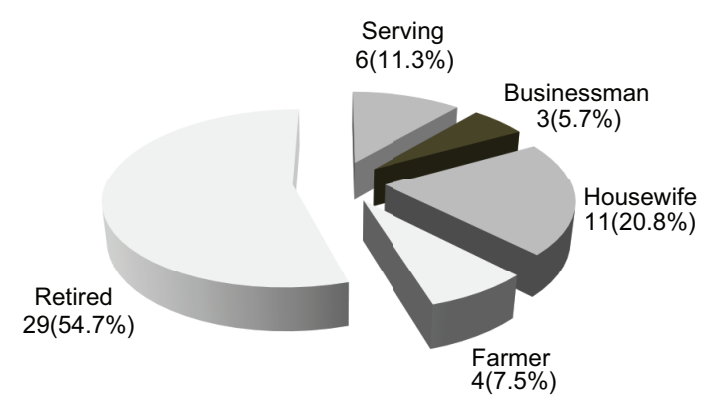

Fig.-1: Pie chart showing the distribution of study population by occupational status $(n=53)$. 


\section{Characteristics of pressure ulcer}

Majority 37 (69.8\%) had single number of pressure ulcer followed by $13(24.5 \%)$ had 2 pressure ulcers where 3 $(5.7 \%)$ had 3 or more pressure ulcer. $27(51.9 \%)$ of study population had developed pressure ulcer on buttock followed by 20 (38.5\%) had developed pressure ulcer on sacrum and $43(81.1 \%)$ had developed pressure ulcer after admission. Majority $16(30.2 \%)$ were admitted in geriatric HDU ward followed by $10(18.9 \%)$ were admitted in officers ward (Table II).

\section{Table II}

Distribution of study population by characteristics of pressure ulcer $(n=53)$

\begin{tabular}{|c|c|c|c|}
\hline Characteristics & Categories & requency & Percentage \\
\hline Number of pressure & 1 & 37 & 69.8 \\
\hline \multirow[t]{2}{*}{ ulcer } & 2 & 13 & 24.5 \\
\hline & $\geq 3$ & 3 & 5.7 \\
\hline Location (Skin & Ischial & 27 & 51.9 \\
\hline \multirow[t]{6}{*}{ overlying) } & Pre-sacral & 20 & 38.5 \\
\hline & Back of Thigh & 11 & 21.2 \\
\hline & Elbow & 1 & 1.9 \\
\hline & Shoulder & 1 & 1.9 \\
\hline & Back & 3 & 5.8 \\
\hline & Ankle & 2 & 3.8 \\
\hline Time of & Before admission & 10 & 18.9 \\
\hline development & After admission & 43 & 81.1 \\
\hline \multirow[t]{9}{*}{ Admitted ward } & Critical Care Centre & re 5 & 9.4 \\
\hline & Geriatric HDU & 16 & 30.2 \\
\hline & Medical HDU & 3 & 5.7 \\
\hline & Surgical HDU & 1 & 1.9 \\
\hline & Burn and plastic & 1 & 1.9 \\
\hline & Neurosurgery & 3 & 5.7 \\
\hline & Neuromedicine & 8 & 15.1 \\
\hline & Orthopedic & 6 & 11.3 \\
\hline & Officers ward & 10 & 18.9 \\
\hline
\end{tabular}

Among the 53-study population maximum 35 (66.0\%) of study population belonged to stage II pressure ulcer followed by $10(18.9 \%)$ belonged to stage I where 7 (13.2\%) belonged to stage III and rest $1(1.9 \%)$ belonged to stage IV pressure ulcer (Figure 2).

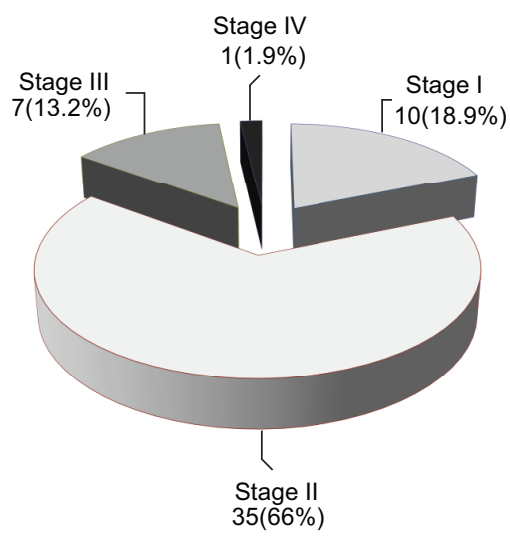

Fig.-2: Pie chart showing the distribution of study population by stage of pressure ulcer $(n=53)$.

\section{Associated factors contributing for developing pressure ulcer.}

Majority 15 (28.3\%) of study population were admitted for d"10 days in hospital followed by $11(20.8 \%)$ were admitted between 11-20 days and 10 (18.9\%) were admitted between 21-30 days where mean length of stay were 29.66 days with standard deviation \pm 34.662 days (Figure 3).

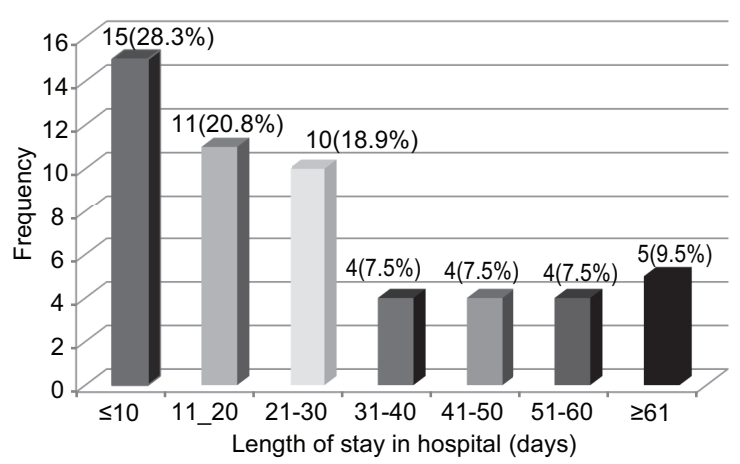

Fig.-3: Bar chart showing the distribution of study population by length of stay in hospital $(n=53)$.

In this study various associated factors are observed contributing development of pressure ulcer (Table III). 
Table III

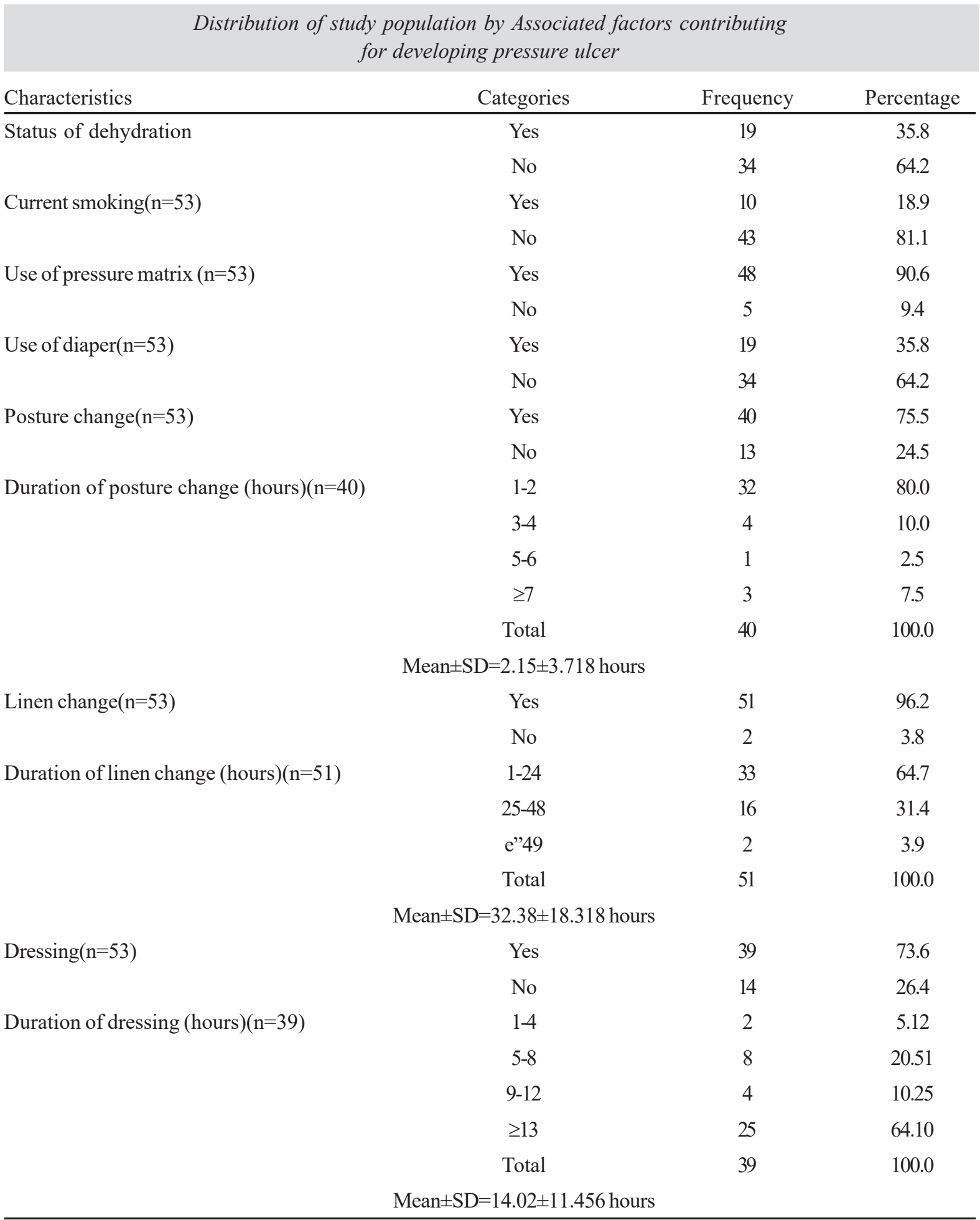

Maximum 45 (84.9\%) were suffered from Hypertension. Other major co-morbidities were Cerebrovascular disease 39 (73.6\%), Diabetes 24(45.3\%), IHD 16(30.2\%) and Pneumonia 12 (22.6\%) (Table IV). 


\section{Table-IV}

Distribution of study population by morbidity status

\begin{tabular}{lcc} 
Morbidity type & Frequency & Percentage \\
\hline Diabetes & 24 & 45.3 \\
CVD & 39 & 73.6 \\
After prolong surgery & 6 & 11.3 \\
Bronchial asthma & 12 & 22.6 \\
Parkinson's disease & 11 & 20.8 \\
Hypertension & 45 & 84.9 \\
Pneumonia & 12 & 22.6 \\
Fracture of Hip or Femur & 8 & 15.1 \\
Ischemic heart disease & 16 & 30.2 \\
Fracture of any other bone & 5 & 9.4 \\
Cancer & 3 & 5.7 \\
Multi organ dysfunction & 11 & 20.8 \\
Kidney injury & 9 & 17.0 \\
Electrolyte imbalance & 10 & 18.9 \\
Dementia & 3 & 5.7 \\
Burn & 1 & 1.9 \\
\hline
\end{tabular}

Note: Due to multiple response the total percentage is more than $100 \%$.

\section{Assessment of the severity of risk for developing pressure ulcer (Braden Scale)}

According to Braden scale, maximum 25 (47.2\%) had slightly limited sensory perception and $30(56.6 \%)$ belonged to occasionally moist group. All 53 (100.0\%) respondents were bedfast. Majority 27 (50.9\%) were completely immobile, 35 (66\%) had adequate nutrition and $30(56.6 \%)$ had problem with friction and shear (Table V).

Among the 53- study population majority 27 (50.9\%) had high risk for development of pressure ulcer followed by $14(26.4 \%)$ had moderate risk for developing pressure ulcer and there was not a single study population who had no risk for developing pressure ulcer (Figure IV). Mean Braden score was 12.25 with standard deviation \pm 2.028 .

\section{Table V}

\section{Distribution of study population by Braden Scale}

\begin{tabular}{llcc} 
Characteristics & Categories & Frequency & Percentage \\
\hline Sensory & Completely limited & 00 & 00 \\
perception & Very limited & 14 & 26.4 \\
& Slightly limited & 25 & 47.2 \\
& No impairment & 14 & 26.4 \\
Moisture & Constantly moisture & 2 & 3.8 \\
& Often moisture & 21 & 39.6 \\
& Occasionally moisture & 30 & 56.6 \\
& Rarely moist & 00 & 00 \\
Activity & Bed fast & 53 & 100.0 \\
& Chair fast & 00 & 00.0 \\
& Walks occasionally & 00 & 00.0 \\
& Walks frequently & 00 & 00.0 \\
Mobility & Completely immobile & 27 & 50.9 \\
& Very limited & 20 & 37.7 \\
Nutritional & Slightly limited & 6 & 11.3 \\
status & Very poor & 1 & 1.9 \\
& Probably inadequate & 17 & 32.1 \\
& Adequate & 35 & 66.0 \\
Friction and & Excellent & 00 & 00 \\
shear & Problem & 30 & 56.6 \\
& Potential problem & 22 & 41.5 \\
& No apparent problem & 1 & 1.9 \\
\hline
\end{tabular}

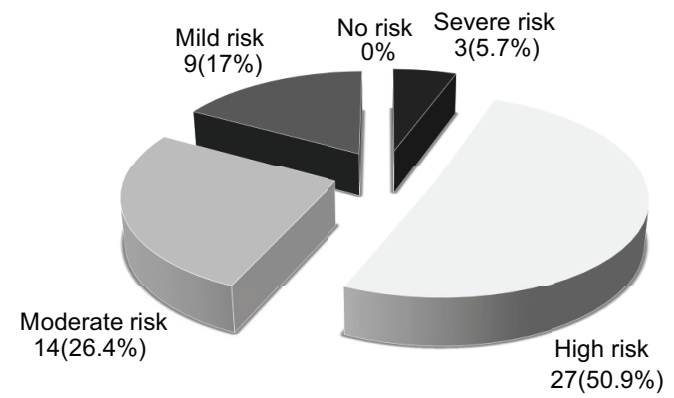

Fig.-4: Pie chart showing distribution of study population by risk of development of pressure ulcer $(n=53)$.

In statistical analysis, age group of 60-90 years, SSC \& above educational group, male sex, immobility, low Braden score group patients are statistically significant $(\mathrm{p}<0.05)$, and hypertensive and cerebrovascular diseased patients are not statically significant $(p>0.05)$ to develop pressure ulcer (Table VI). 
Table VI

\section{Statistical significance of different associated factors}

\begin{tabular}{|c|c|c|c|c|c|c|c|c|c|}
\hline \multicolumn{2}{|c|}{ Age } & \multicolumn{4}{|c|}{ After admission } & \multicolumn{3}{|c|}{ Before admission } & \multirow[t]{3}{*}{$\mathrm{P}=0.03$} \\
\hline \multicolumn{2}{|l|}{ Less 60} & \multicolumn{4}{|l|}{12} & \multicolumn{3}{|l|}{7} & \\
\hline \multicolumn{2}{|l|}{$60-90$} & \multicolumn{4}{|l|}{30} & \multicolumn{3}{|l|}{4} & \\
\hline \multicolumn{2}{|c|}{$\begin{array}{l}\text { Educational } \\
\text { status }\end{array}$} & \multicolumn{4}{|c|}{ No of Pressure Ulcer (1-2) } & \multicolumn{3}{|c|}{ No of Pressure Ulcer (3-5) } & \multirow[t]{3}{*}{$\mathrm{P}=0.003$} \\
\hline \multicolumn{2}{|c|}{ Upto secondary } & \multicolumn{4}{|l|}{13} & \multicolumn{3}{|l|}{6} & \\
\hline \multicolumn{2}{|c|}{ SSC and above } & \multicolumn{4}{|l|}{33} & \multicolumn{3}{|l|}{1} & \\
\hline \multicolumn{2}{|c|}{$\begin{array}{l}\text { Sex } \quad \text { (Place } \\
\text { of admission) }\end{array}$} & \multicolumn{2}{|c|}{$\begin{array}{c}\text { Critical } \\
\text { CareCentre } \\
\text { No }(\%)\end{array}$} & $\begin{array}{c}\text { HDU } \\
\text { No }(\%)\end{array}$ & $\begin{array}{l}\text { Neuro- } \\
\text { surgery } \\
\text { No }(\%)\end{array}$ & $\begin{array}{c}\text { Neuro- } \\
\text { medicine } \\
\text { No }(\%)\end{array}$ & $\begin{array}{c}\text { Ortho- } \\
\text { pedic } \\
\text { No }(\%)\end{array}$ & $\begin{array}{c}\text { Officers } \\
\text { ward No } \\
(\%)\end{array}$ & \multirow[t]{3}{*}{$\mathrm{P}=0.009$} \\
\hline \multicolumn{2}{|l|}{ Male } & \multicolumn{2}{|c|}{$3(5.7)$} & $12(22.6)$ & $3(5.7)$ & $8(15.1)$ & $6(11.3)$ & $10(18.9)$ & \\
\hline \multicolumn{2}{|l|}{ Female } & \multicolumn{2}{|c|}{$2(3.8)$} & $8(15.1)$ & $0(0.0)$ & $0(0.0)$ & $0(0.0)$ & $0(0.0)$ & \\
\hline \multicolumn{5}{|l|}{ Mobility } & \multicolumn{2}{|c|}{ Frequency } & \multicolumn{2}{|c|}{ Percentage } & $\mathrm{P}=0.041$ \\
\hline Completely & nob & e/ Very & ited & 4 & & & 88.7 & & \\
\hline Slightly lim & & & & 6 & & & 11.3 & & \\
\hline Braden Sc: & & & & & uency & & Percenta & & $\mathrm{P}=0.043$ \\
\hline Severe to $\mathrm{H}$ & Ris & & & 3 & & & 56.6 & & \\
\hline Mild to Mo & te $\mathrm{F}$ & & & 2 & & & 43.4 & & \\
\hline Morbidity & & perten- & CVD & Diabet & IHD & $\begin{array}{l}\text { Bronchial } \\
\text { Asthma/ } \\
\text { Pneum-onia }\end{array}$ & $\begin{array}{l}\text { Multi-orga } \\
\text { dysfunction } \\
\text { Parkinson' }\end{array}$ & Other & $\mathrm{P}=0.051$ \\
\hline Frequency & 45 & & 39 & 24 & 16 & 12 & 11 & $1-10$ & \\
\hline Percentage & 84 & & 73.6 & 45.3 & 30.2 & 22.6 & 20.8 & $1.9-18.9$ & \\
\hline
\end{tabular}

\section{Discussion:}

In the present study it was found that about half (50.9\%) of the study population were in the age group 61-80 years. The mean age of the study population were 69.13 years. This study findings were almost similar to the study findings conducted by Banjar et al in Jeddah, Saudi Arabia where it was found that $60 \%$ of the study population had developed pressure ulcer between the age 60-90 years 9 . The study findings were not similar to the study findings conducted by Amin et al in Bangladesh where it was found that $41.2 \%$ of study population had developed pressure ulcer between the age $21-40$ years ${ }^{10}$. A study conducted by Zhou et al in china where majority $(37.7 \%)$ had developed pressure ulcer between age $40-60$ years ${ }^{11}$. This study findings were not similar to the present study findings due to defense persons were less prone to develop pressure ulcer in early age due to their physical fitness in service period.

As per sex distribution among the study population it was revealed that about four fifth $(79.2 \%)$ of study population were male and one fifth $(20.8 \%)$ were female which is almost similar to the study findings conducted by Amin et al in Bangladesh (77.2\% were male and 22.8\% were female and Arsh et al (2016) in Pakistan (77.8\% were male and $22.2 \%$ were female) $)^{10,12}$.

In the present study it was seen that majority (69.8\%) had developed one pressure ulcer followed by $24.5 \%$ had developed 2 pressure ulcer and $5.7 \%$ had developed 3 or more pressure ulcer. Among the study population majority $12(22.6 \%)$ of study population of SSC or equivalent had single number of pressure ulcer followed by $11(20.8 \%)$ study population of degree and above had single number of pressure ulcer. The association between number of pressure ulcer and educational status was found statistically significant $(\mathrm{p}=0.046)$ which is nearly similar to study conducted by Baumgarten et al in $\mathrm{USA}^{13}$.

In the present study it was evident that $51.9 \%$ and $38.5 \%$ of study population had developed pressure ulcer skin overlying in ischial and pre-sacral respectively. This study findings were dissimilar to the study findings conducted by Sharmila et al Bangladesh and Arsh et al in Pakista may be due to frequent change of posture of 
the present study population. Further study may be required to find out the cause of difference ${ }^{14,12}$.

In the present study it was revealed that two third $(66.0 \%)$ of study population had stage II pressure ulcer followed by $18.9 \%$ had stage I pressure ulcer which were not similar to the study findings conducted by Baumgarten et al in USA ${ }^{13}$ and Bernardes et $\mathrm{al}^{15}$. Further in-depth study is required to find out the cause of dissimilarity ${ }^{14,12}$.

Among all one fourth (28.3\%) of study population were admitted for d" 10 days in hospital followed by $20.8 \%$ were admitted between 10-20 days where mean duration of stay 29.66 days. This study findings were dissimilar to the study findings conducted Banjar et al in Saudi Arabia where it was found that majority $62.5 \%$ were stayed in hospital for 5-10 days 9 . Further study may be required to find out the cause of difference.

This study revealed that more than three fourth $(84.9 \%)$ $\%$ of study population had hypertension, $73.6 \%$ had cerebrovascular disease, $45.3 \%$ had diabetes, $22.6 \%$ had asthma which were not similar to the study findings conducted by Margolis et al conducted in USA ${ }^{16}$. Again, this dissimilarity can be address in future study to find out the cause.

In the present study it was found that about half $(50.9 \%)$ of study population had high risk for developing pressure ulcer followed by $26.4 \%$ of study population had moderate risk for developing pressure ulcer. The present study findings were not similar to the study findings conducted by Zhou et al in China where it was found that majority $79.7 \%$ had no risk for development of pressure ulcer followed by $11.8 \%$ had low risk for development of pressure ulcer ${ }^{11}$. On the other hand, this study findings were more or less similar to the study findings by Karahan et al and Akca et al conducted in Turkey ${ }^{17,18}$. Being a present cross-sectional study, this similarity/dissimilarity appears to be beyond the scope of explanation. We may expect future study to explain those things.

In statistical analysis, we found higher age group, SSC $\&$ above educational group, male sex, immobility, low Braden score group patients are statistically significant $(\mathrm{p}<0.05)$, and hypertensive and cerebrovascular diseased patients are not statically significant $(\mathrm{P}>0.05)$ but having clear trends to be associate factors to develop pressure ulcer.
Finally, as this study has limitation of being short duration single centered with small sample size, further large size multicentered study is required to confirm the study findings.

\section{Conclusion:}

In a tertiary level military hospital like CMH Dhaka higher age group, male sex, immobilization, low Braden score, hypertensive and cerebrovascular diseased patients were more prone for development of pressure ulcer among the critically ill patients. Pressure ulcers are a serious issue for patients in all kinds of settings. In the light of this study findings, it is told that early detection of pressure ulcer should be a part of initial management of patients those who are critically ill.

\section{Recommendations:}

1. Measures should be taken for prevention of pressure ulcer specially among higher aged group (61-80 years).

2. Special preventive care should be taken for the pressure ulcer patients admitted in geriatric unit of HDU and officers ward specially after admission into hospital.

3. Health awareness programme/Counseling and deliberate/comprehensive pressure ulcer prevention programme should be taken among the critically ill patients who are bed ridden with special attention to male patients.

4. Regular posture should be changed to all patients who are unable to move.

5. Patient's as well as caregiver education regarding management \& prevention of pressure ulcer has significant role. So it should be given priority.

\section{References:}

1. Mathison, C.J., 2003. Skin and wound care challenges in the hospitalized morbidly obese patient. Journal of WOCN, 2003 Nov 30(2), pp.78-83.

2. Roberts BV, Goldstone LA. A survey of pressure sores in the over sixties on two orthopaedic wards. International Journal of Nursing Studies. 1979 Jan 1;16(4):355-64.

3. Black, J., Baharestani, M.M., Cuddigan, J., Dorner, B., Edsberg, L., Langemo, D., Posthauer, M.E., Ratliff, C. and Taler, G., 2007. Aug 20(5), pp.269-274.

4. Haalboom JR. The Dutch experience of pressure ulcers-a personal view. Journal of wound care. 2000 Mar;9(3): 121-2. 
5. Prentice JL, Stacey MC, Lewin G. An Australian model for conducting pressure ulcer prevalence surveys. Primary Intention: The Australian Journal of Wound Management. 2003 May;11(2):87.

6. Suriadi, Sanada H, Sugama J, Kitagawa A, Thigpen B, Kinosita $\mathrm{S}$, Murayama S. Risk factors in the development of pressure ulcers in an intensive care unit in Pontianak, Indonesia. International wound journal. 2007 Sep;4(3):208-15.

7. Registered Nurses' Association of Ontario, Virani T. Risk assessment \& prevention of pressure ulcers. Registered Nurses Association of Ontario. 2005 Feb 2(2):25-7.

8. Armstrong D, Bortz P. An integrative review of pressure relief in surgical patients. AORN journal. 2001 Mar 1;73(3):645-74.

9. Banjar H, Mahran S. Effectiveness of prevention and management of pressure ulcers, as "a patient safety issues" among bed ridden Patients at King Abdul Aziz University Hospital in Jeddah, Saudi Arabia. Journal of American Science. 2012;8(6).

10. Amin MR, Haque MM, Saha PK, Zai SZ, Hossain SM, Akter S. Pattern and risk assessment of bedsore in hospitalized patients. Chattagram Maa-O-Shishu Hospital Medical College Journal. 2014 Nov 30;13(2):12-6.

11. Zhou Q, Yu T, Liu Y, Shi R, Tian S, Yang C, Gan H, Zhu Y, Liang X, Wang L, Wu Z. The prevalence and specific characteristics of hospitalised pressure ulcer patients: A multicentre cross sectional study. Journal of clinical nursing. 2018 Feb;27(3-4):694-704.
12. Arsh A, Darain H, Ilyas SM, Zeb A. Prevelacne of pressure ulcers in patients with spinal cord injury; a retrospective study. Pakistan Journal of Neurological Sciences (PJNS). 2012;11(4):16-21.

13. Baumgarten M, Margolis DJ, Localio AR, Kagan SH, Lowe RA, Kinosian B, Holmes JH, Abbuhl SB, Kavesh W, Ruffin A. Pressure ulcers among elderly patients early in the hospital stay. The Journals of Gerontology Series A: Biological Sciences and Medical Sciences. $2006 \mathrm{Jul}$ 1;61(7):749-54.

14. Sharmila J. Prevalence of pressure sore among the spinal cord injury patients at CRP (Doctoral dissertation, Department of Physiotherapy, Bangladesh Health Professions Institute, CRP). 2014;9(2):122-27

15. Bernardes RM, Caliri MH. Pressure ulcer prevalence in emergency hospitals: a cross-sectional study. Online Brazilian Journal of Nursing. 2016;15(2):236-44.

16. Margolis DJ, Knauss J, Bilker W, Baumgarten M. Medical conditions as risk factors for pressure ulcers in an outpatient setting. Age and ageing. 2003 May 1;32(3):259-64.

17. Karahan A, AAbbasoðlu A, Ipýk SA, Cevik B, Saltan C, Elbap NÖ, Yalýlý A. Factors Affecting Wound Healing in Individuals With Pressure Ulcers: A Retrospective Study. Ostomy/wound management. 2018 Feb;64(2):32.

18. Akca NK, Aydin G, Gümüs K. Pressure ulcers and their associated factors in nursing home inmates. J Coll Physicians Surg Pak. 2015 Jan 1;25(1):27-30. 